\title{
Integration of word pair responses in paired associate learning
}

PHYLLIS GREENHOUSE, DEPARTMENT OF PSYCHOLOGY, ADELPHI UNIVERSITY, Garden City, N. Y. 11530

Separate lists of single words (SW), of primary associates with word pairs highly integrated (HI) and of unrelated word pairs of a low degree of integration ( $L I)$, were presented to independent groups in a paired associate learning task. The $S W$ and HI groups did not differ in number of trials to the criterion of one errorless trial, while the LI groups took significantly longer than both.

In recent years response integration has been afforded a prominent role in transfer theory (Mandler, 1962; Martin, 1965) and in the two stage conception of paired associate (PA) learning (Underwood \& Schulz, 1960). The conventional response materials that have been used to demonstrate the effects of response integration have differed in meaningfulness (M) with either CVCs or CCCs as the low $\mathrm{M}$ items and either adjectives or nouns as the high $M$ items. Even a cursory examination of these materials reveals that they vary in frequency-of-occurrence, the likelihood of formal similarity as well as degree of integration. It has also been shown (Houston, 1965) that the rate of forgetting of a verbal unit is directly related to the number of elements in the unit, implying that nonsense syllables comprised of three elements in comparison with words that function as one element may have distorted the influence of the $M$ variable.

The present study was undertaken in an attempt to develop materials that would differ only to the extent to which the elements were integrated while controlling the other dimensions. Under the assumption that integration and association are synonymous, lists of word pairs were constructed in which the words were primary associates in established norms (Palermo \& Jenkins, 1964) indicating that they have a high degree of integration (HI). Using the same first words but selecting words never given as associates to serve as the second words, lists of word pairs of a low degree of integration (LI) were also constructed.

In order to assess that the HI lists could function as highly integrated response materials in PA learning the performance of independent groups getting the $\mathrm{HI}$, and LI lists was compared with

Table 1

Stimuli and Words for Single (SW), High Integrated (HI, and Low Integrated (LI) Lists

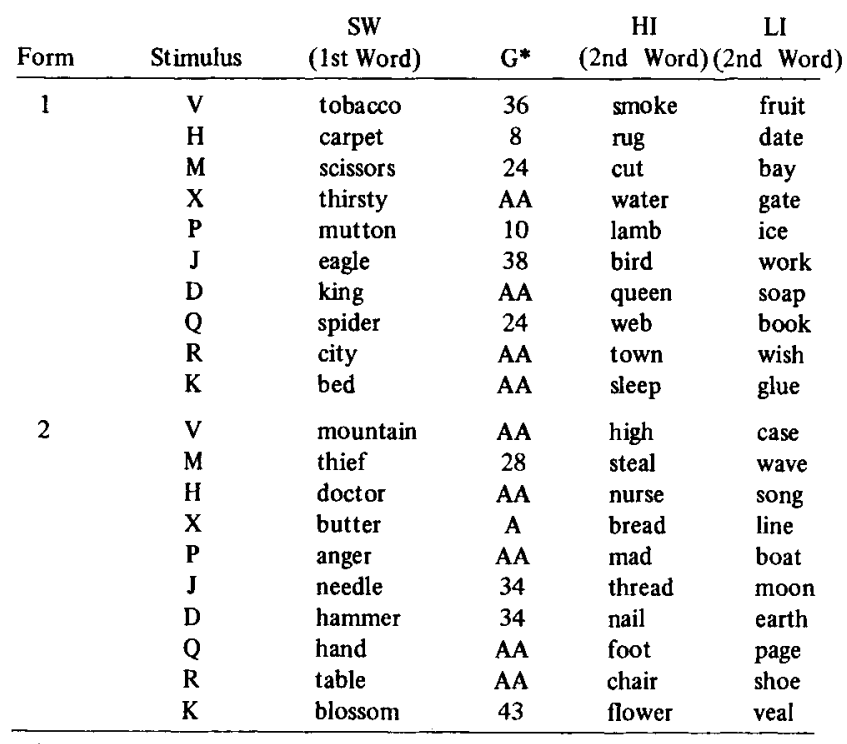

$G^{*}$ : Thorndike-Lorge G count.

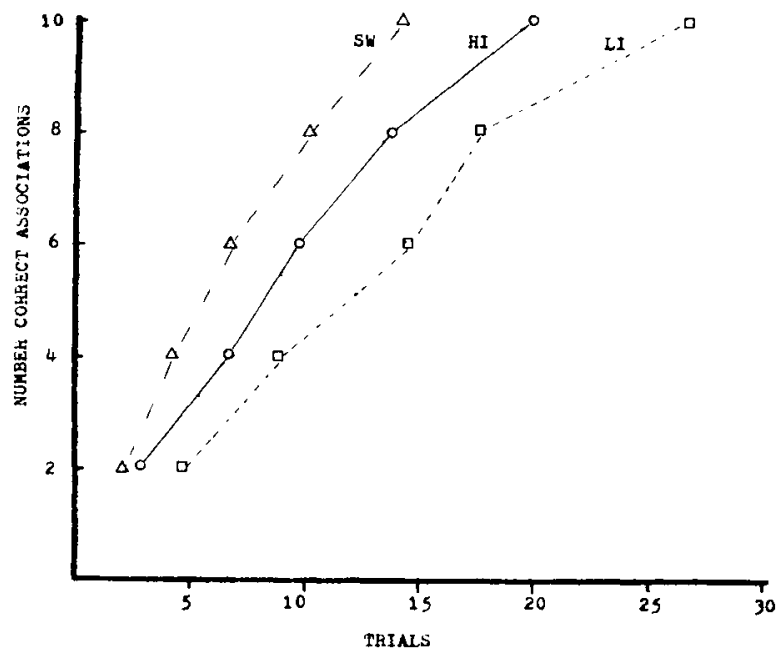

Fig. 1. Mean number of trials to criterion of one perfect trial.

groups getting lists of just the first words, that is a list of single word (SW) responses.

It was predicted that if the HI words functioned as highly integrated there would be no reliable difference in the number of trials to criterion between the HI and SW groups, while the LI groups would take significantly longer than both.

Subjects. There were $13 \mathrm{Ss}$ in. each of six groups making a total of $78 \mathrm{Ss}$. The Ss were assigned on a random basis with the restriction that no cell contained $n+1$ Ss until all cells contained $n$ Ss. The Ss were undergraduate students whose native language was English and who served in order to fulfill a course requirement.

Lists. The learning materials were six lists of 10 paired associates with single consonant stimuli. (Table 1.) The first word responses were nouns (except for one adjective, thirsty) taken from the Palermo \& Jenkins (1964) norms. The integration requirements were met by pairing with a second word that was either a primary associate (HI) in the norms or a word never given as associate (LI). These LI second words were selected according to the following restrictions: (a) Never given as an associate in norms, (b) Monosyllabic nouns, (c) Frequency of AA on Thorndike-Lorge G count. The single word (SW) list had only the first words of the word pairs as responses.

Procedure. There were six independent groups representing the two integration levels and the single list with two forms of each list. Following the reading of standard $\mathrm{PA}$ instructions, training was continued until each $\mathrm{S}$ reached a criterion of one perfect trial.

The lists were presented on a Stowe memory drum at a 2:2 rate with a $4 \mathrm{sec}$ intertrial interval with three different random orders to minimize serial learning.

Results and Discussion. The analysis of variance for the three types of lists (SW, HI, LI) and two forms $(1,2)$ revealed only a significant list effect $(F=24.47, \mathrm{df}=2 / 72, \mathrm{p}<.001)$ which was due to the LI groups taking significantly more trials to reach criterion. (Fig. 1.) Thus, the predictions of no difference between the SW and HI groups with reliable differences of both from the LI were supported. Combining the forms the mean number of trials to criterion were $13.96,19.50$ and 26.81 for the $\mathrm{SW}, \mathrm{HI}$ and LI conditions, respectively.

Response integration can be defined as the process of associating or uniting formerly discrete elements into a response sequence so that they form a behavioral unit (Mandler, 1954, 1962). In line with this definition and in consideration of the controls exercised, the $\mathrm{HI}$ and LI word pairs have been shown to vary in degree of integration which should make them particularly well suited to tests of the role of response integration in two stage learning tasks. 


\section{REFERENCES}

HOUSTON, J. P., Short-term retention of verbal units with equated degrees of learning. J. exp. Psychol, 1965, 70, 75-78.

MANDLER, G., Response factors in human learning. Psychol. Rev., 1954, 61, 235-244.

MANDLER, G., From association to structure. Psychol. Rev., 1962, 69,
415427.

MARTIN, E., Transfer of verbal paired associates. Psychol. Rev., 1965, 72, 327-343.

PALERMO, D. S., \& JENKINS, J. J. Word association norms. Grade school through college. Minneapolis: University of Minnesota Press, 1964

UNDERWOOD, B. J., \& SCHULZ, R. W., Meaningfulness and verbal learning. Phildelphia: Lippincott, 1960. 